\title{
A Phosphatase Activity Present in Peripheral Blood Myeloid Cells of Chronic Myelogenous Leukemia Patients but Not Normal Individuals Alters Nuclear Protein Binding to Transcriptional Enhancers of Interferon-inducible Genes
}

David C. Seong, Simon Sims, Elizabeth Johnson, O. M. Zack Howard, Brian Reiter, Jeane Hester, Moshe Talpaz, Hagop Kantarjian, and Albert Deisseroth

Departments of Hematology, and Clinical Immunology and Biological Therapy,

University of Texas M. D. Anderson Cancer Center, Houston, Texas 77030

\begin{abstract}
Cytoplasmic protein from peripheral blood myeloid cells of chronic myelogenous leukemia (CML) patients altered the electrophoretic mobility of complexes formed between nuclear proteins and interferon-inducible transcriptional enhancers. Immature myeloid marrow cells (blasts and promyelocytes) have a higher level of this activity than do mature myeloid marrow cells (bands and polys). This activity, which is not detectable in the peripheral blood cells of normal individuals, is at least 50-fold higher in CML marrow blasts and promyelocytes than that found in marrow blasts and promyelocytes of normal individuals. This activity was inhibited by in vivo incubation of immature myeloid cells with the phosphatase inhibitor, sodium orthovanadate $(0.2 \mathrm{mM})$, and by adding orthovanadate $(20 \mathrm{mM})$ directly to cytoplasmic proteins of myeloid cells. Interferon- $\alpha(1,000 \mathrm{U} / \mathrm{ml})$ reduced the effects of the CML myeloid cell cytoplasmic protein on the electrophoretic mobility of nuclear protein-DNA complexes. These data suggest that a unique phosphatase may be involved in the abnormalities in CML which are modulated by interferon- $\alpha$. ( $J$. Clin. Invest. 1990. 86:1664-1670.) Key words: chronic myelogenous leukemia • interferon - nuclear proteins • transcriptional enhancers
\end{abstract}

\section{Introduction}

Chronic myelogenous leukemia $(\mathrm{CML})^{1}$ begins with a benign phase which lasts an average of $3.5 \mathrm{yr}$. The disease then evolves into a more serious blastic crisis in which patients die of bleeding and infection (1). Two treatments, bone marrow transplantation and interferon- $\alpha$, may delay the onset of the blastic transformation $(2,3)$. Only $25 \%$ of patients have an HLA-matched related allograft donor and only $15 \%$ of earlyphase CML patients achieve a complete cytogenetic remission with interferon- $\alpha$ treatment $(4,5)$. The mechanism through which interferon- $\alpha$ mediates its clinical effect in CML and the

Address reprint requests to Dr. Deisseroth, Department of Hematology, Box 24, M. D. Anderson Cancer Center, 1515 Holcombe Boulevard, Houston, TX 77030.

Received for publication 7 February 1990 and in revised form 20 June 1990

1. Abbreviations used in this paper: $\mathrm{CML}$, chronic myelogenous leukemia; 2,5-OAS, 2,5-oligoadenylate synthetase.

J. Clin. Invest.

(C) The American Society for Clinical Investigation, Inc.

0021-9738/90/11/1664/07 \$2.00

Volume 86, November 1990, 1664-1670 reasons for the variable levels of sensitivity to interferon are unknown.

Interferon- $\alpha$ exerts its effects in many cells by activating the transcription of genes that code for immunomodulatory proteins such as histocompatibility antigens and $\beta_{2}$-microglobulin (6), for antiviral enzymes (7) such as 2,5-oligoadenylate synthetase (2,5-OAS), and for interferon-inducible proteins of unknown function such as 9-27 and 6-16 $(8,9)$. This transcriptional activation is mediated through alteration of nuclear proteins that bind to the $5^{\prime}$ transcriptional enhancers of interferon-inducible genes before the activation of gene expression (10).

In the course of a study designed to determine if the clinical effect of interferon- $\alpha$ in CML was in any way related to transcriptional activation of interferon-inducible genes, we found that the transcriptional enhancers of interferon-inducible genes were functional in normal and CML myeloid cells, and that differences existed between the electrophoretic mobility of complexes formed between these interferon-inducible transcriptional enhancers and the nuclear proteins of normal and CML cells (11).

Here we report that the cytoplasmic proteins isolated from CML cells contain an enzymatic activity that alters the electrophoretic mobility of the complexes formed between nuclear proteins and the transcriptional enhancers of interferon-inducible genes. This activity is not detectable in peripheral blood cells of normal individuals. This enzymatic activity, which is found in the cytoplasm of immature marrow myeloid cells, was 50-fold greater in CML myeloid blasts and promyelocytes than in the marrow blasts and promyelocytes of normal individuals. Our studies suggest that this activity is an acid phosphatase which is modulated by interferon- $\alpha$.

\section{Methods}

In vivo and in vitro use of interferon- $\alpha$. In vitro experiments involved the use of $1,000 \mathrm{U} / \mathrm{ml}$ of recombinant interferon- $\alpha$ at $37^{\circ} \mathrm{C}$ at $\mathrm{pH} 7.4$ for $1 \mathrm{~h}$. The concentration used for in vitro experiments $(1,000 \mathrm{U} / \mathrm{ml}$ for $24 \mathrm{~h})$ is four times the peak serum level usually seen in vivo $2 \mathrm{~h}$ after a subcutaneous injection of $5 \times 10^{6} \mathrm{U}$ of recombinant interferon- $\alpha$.

Isolation of lymphocytes and myeloid cells. Lymphocytes and myeloid cells of different stages of maturation were separated on Percoll gradients from bone marrow and peripheral blood (12). The stage of maturation of myeloid fractionated cells was verified by Wright-Giemsa staining.

Nuclear proteins. Nuclear protein extracts were prepared either according to Miskimens et al. (13) or Dignam et al. (14). Both nuclear and cytoplasmic proteins were dialyzed against buffer "D" (14). 
Cytoplasmic proteins. Cells were lysed by the method of Dignam et al. (14) and the nuclei were pelleted. The cytoplasmic protein was isolated as a supernatant activity.

Mobility-shift assays. The binding of nuclear proteins to interferon-inducible transcriptional enhancers was studied by mobility-shift assays as outlined previously (11,13-15). Binding conditions are the following: Hepes $12 \mathrm{mM}$, glycerol $10 \%$, $\mathrm{KCl} 60 \mathrm{mM}$, EDTA $0.12 \mathrm{mM}$, DTT $0.3 \mathrm{mM}$, EGTA 0.05 $\mathrm{mM}$, and $\mathrm{MgCl} 12 \mathrm{mM}$. The nuclear proteins were preincubated with poly (dI) poly $(\mathrm{dC})$ at a concentration of $0.1 \mathrm{mg} / \mathrm{ml}$ for $15 \mathrm{~min}$ at $40^{\circ} \mathrm{C}$, and then were incubated for $30 \mathrm{~min}$ at $22^{\circ} \mathrm{C}$ with $100 \mathrm{fmol}\left(10^{5} \mathrm{cpm}\right)$ of an oligonucleotide which contains the transcriptional enhancer of the interferon-inducible gene. The oligonucleotides were ${ }^{32} \mathrm{P}$-labeled in the $3^{\prime}$ recessed ends by the Klenow reaction. All incubations were carried out in the presence of the protease incubators $0.005 \mu \mathrm{g} / \mu \mathrm{l}$ aprotinin, $1 \mathrm{mM}$ benzamidine, and $1 \mathrm{mM}$ PMSF. The nuclear protein-DNA complexes were separated from the unbound oligonucleotide by electrophoresis in a $7.5 \%$ polyacrylamide nondenaturing gel at $120 \mathrm{~V}$ for $18 \mathrm{~h}$ in a Tris-acetate buffer (Tris $50 \mathrm{mM}, \mathrm{pH} \mathrm{7.9,} \mathrm{NaOAc} 3.3 \mathrm{mM}$, and EDTA $1.0 \mathrm{mM}$ ).

\section{Results}

Cytoplasmic proteins of CML peripheral blood cells alter electrophoretic mobility of nuclear protein-transcriptional enhancer complexes. Nuclear proteins isolated from a lymphoid cell line (Daudi) formed a single low-mobility complex (band $A$ ) with the interferon-inducible transcriptional enhancers of the human $\beta_{2}$-microglobulin gene (lane 4, Fig. 1, left panel), the 6-16 gene (lane 7, Fig. 1, left panel), the 9-27 gene (lane 1, Fig. 1, left panel), and the antiviral interferon-inducible gene 2,5-OAS as shown in lane 1 , Fig. 1, right panel. These transcriptional enhancers (see Table I) have been reported by others to mediate the transcriptional activation of interferoninducible genes in an orientation-independent manner (6-10).

When we added the cytoplasmic protein of CML peripheral blood cells in a 1:1 ratio (by weight) to the nuclear proteins extracted from the Daudi lymphoid cell line, a change was induced in the electrophoretic mobility of the complex formed by these lymphoid nuclear proteins with the interferon-inducible transcriptional enhancers. The low-mobility complex (band $A$ in lanes 1,4 , and 7, Fig. 1, left panel, and lane 1 Fig. 1, right panel) was changed to a higher-mobility complex (band $B$ in lanes 2, 5, and 8 of Fig. 1, left panel, and lane 2 Fig. 1, right panel). When the cytoplasmic proteins were isolated from the peripheral blood cells of a patient receiving interferon therapy, the magnitude of the change induced by the cytoplasmic protein of the CML cells was decreased (see lane 3 Fig. 1, right panel). As shown in lane 2, Fig. 1, right panel, when Daudi nuclear proteins were exposed to cytoplasmic proteins from CML peripheral blood cells not exposed to interferon, the ratio of band $A$ to band $B$ was 1.2, whereas the ratio was 3.9 using cytoplasmic proteins from CML peripheral blood cells exposed to interferon- $\alpha$ (see lane 3, Fig. 1, right panel). This sensitivity to the interferon- $\alpha$-induced inhibition of the cytoplasmic activity of CML peripheral blood cells has been shown in our laboratory to correlate with the clinical sensitivity to interferon- $\alpha(11)$.

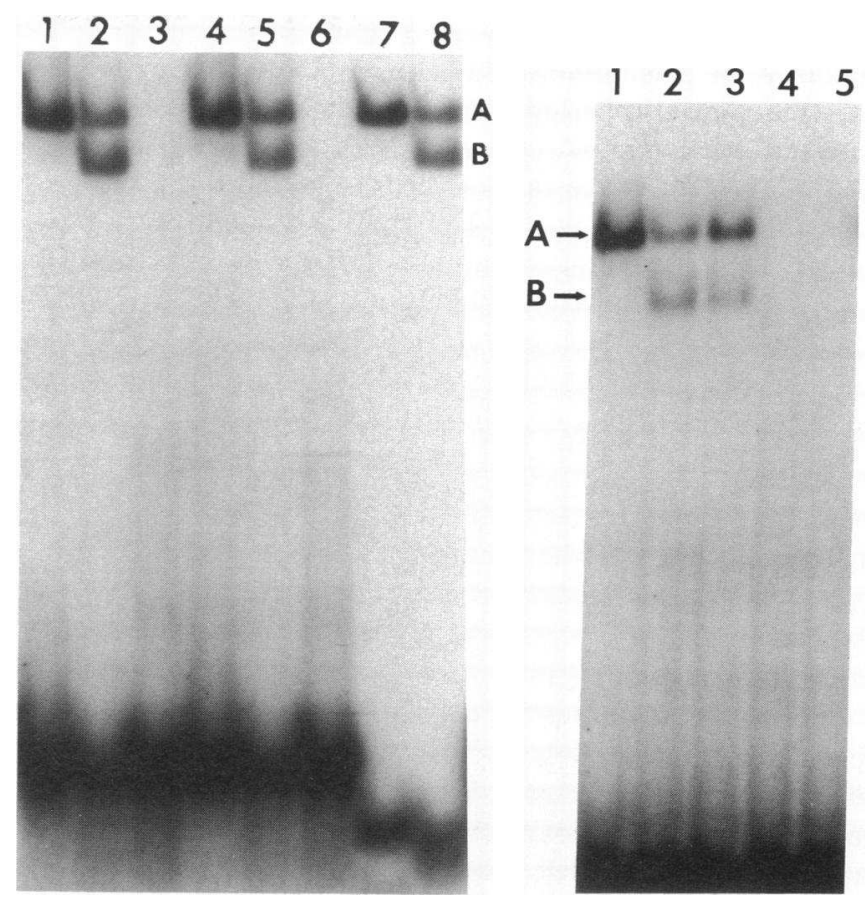

Figure 1. Effect of cytoplasmic protein of CML peripheral blood cells on the electrophoretic mobility of nuclear protein-transcriptional enhancer complexes. We tested the effect of cytoplasmic proteins from CML cells on the electrophoretic mobility of complexes formed between lymphoid nuclear proteins and the interferon-inducible transcriptional enhancers (shown in Table I) of four interferon-inducible genes (9-27, $\beta_{2}$-microglobulin, 6-16, and 2,5-OAS) using the mobility-shift assay. These complexes formed after nuclear proteins were incubated in a 1:1 ratio by weight with cytoplasmic proteins from CML peripheral blood cells for $1 \mathrm{~h}$ at $22^{\circ} \mathrm{C}$. Daudi nuclear protein not incubated with myeloid cytoplasmic extracts was added to the mobility-shift lanes 1,4 , and 7 of the left panel and lane 1 of the right panel. Daudi nuclear protein, after incubation with an equal amount by weight of protein from a cytoplasmic extract of CML peripheral blood cells for $1 \mathrm{~h}$ at $22^{\circ} \mathrm{C}$, was added to the mobility-shift lanes 2,5 , and 8 of the left panel and lane 2 of the right panel. The same amount of protein from a cytoplasmic extract of CML peripheral blood cells was added without Daudi nuclear protein to the mobility-shift lanes 3 and 6 of the left panel. The cytoplasmic protein of CML peripheral blood cells of a patient under interferon- $\alpha$ treatment $\left(5 \times 10^{6}\right.$ units subcutaneously per day $)$ was added to an equal amount by weight to mobility-shift lane 3 of the right panel. Densitometry of the ratio of band $A$ to band $B$ in lanes 2 and 3 of the right panel was used to assess the effect of interferon on the cytoplasmic phosphatase. A ${ }^{32} \mathrm{P}$-labeled oligonucleotide which contains the following interferon-inducible transcriptional enhancers were added to the following mobility-shift lanes: lanes 1-3 of the left panel, 9-27; lanes 4-6 of the right panel, human $\beta_{2}$-microglobulin; lanes 7 and 8 of the left panel, 6-16; and lanes 1-3 of the right panel, 2,5-OAS. Band $A$ is the low-mobility complex between nuclear proteins from Daudi and the interferon-inducible transcriptional enhancer. Band $B$ is the complex formed between the 2,5-OAS transcriptional enhancer and the lymphoid nuclear proteins which had been exposed to the cytoplasmic protein of CML peripheral blood cells. The unbound probe is at the bottom of each mobility-shift lane. Cell incubations were done in the presence of protease inhibitors aprotinin, benzamidine, and PMSF. The nuclear proteins were pre-incubated with a final concentration of $0.1 \mathrm{mg} / \mathrm{ml}$ of poly $(\mathrm{dI})$ poly $(\mathrm{dC})$ before incubation with the transcriptional enhancers. 
To identify the source of the cytoplasmic activity which modified the mobility of the nuclear protein-DNA complex, we fractionated the peripheral blood cells of CML patients into myeloid and lymphoid cells by Percoll gradients. The cytoplasmic protein of the myeloid cells isolated from CML peripheral blood contained an activity that altered the electrophoretic mobility of nuclear protein-DNA complexes (see Fig. 2). When the cytoplasmic protein of lymphoid cells of CML peripheral blood or peripheral blood cells of normal individuals (lymphoid or myeloid) were added to lymphoid nuclear proteins in a 1:1 ratio, no change in the electrophoretic mobility of the complexes formed by lymphoid nuclear proteins and interferon-inducible transcriptional enhancers was noted. The activity of CML peripheral blood myeloid cells, which altered the electrophoretic mobility of these complexes, was absent in the peripheral blood cells of 18 out of 18 normal individuals tested and was present in the peripheral blood cells of 40 out of 44 CML patients tested (11).

The alteration of the electrophoretic mobility of DNA-nuclear protein complexes by the cytoplasmic proteins from CML peripheral blood myeloid cells was observed at $22^{\circ} \mathrm{C} \mathrm{(left}$ panel of Fig. 2) but not at $4^{\circ} \mathrm{C}$ (right panel of Fig. 2) and was time-dependent (see left panel of Fig. 2). All of these changes were observed in the presence of the protease inhibitors aprotinin, benzamidine, and PMSF. These data suggest that the changes in electrophoretic mobility of nuclear protein-DNA complexes were due to an enzymatic activity other than a protease that was present in the cytoplasm of the peripheral blood myeloid cells of CML patients.

Cytoplasmic activity in peripheral blood CML myeloid cells may be an acid phosphatase. When $0.2 \mathrm{mM}$ orthovanadate, an inhibitor of cellular phosphatases (16), was added to intact CML cells before isolation of cytoplasmic protein, the magnitude of the effect of the CML cytoplasmic proteins on the electrophoretic mobility of the lymphoid nuclear protein complex was diminished (Fig. 3, upper left panel). The orthovanadate completely inhibited the cytoplasmic activity of myeloid cells on the Daudi nuclear protein when added in vitro to the cytoplasmic proteins at a concentration of $20 \mathrm{mM}$ (Fig. 3, right panel). These experiments suggested that the cytoplasmic activity in CML myeloid cells that alters the mobility of nuclear protein-DNA complexes is a phosphatase.

This conclusion was formally tested by exposing the complexes formed between the 2,5-OAS transcriptional enhancer oligonucleotide shown in Table I and Daudi cell nuclear proteins in vitro acid phosphatases. The addition of $9 \mathrm{U}$ of potato white acid phosphatase (Sigma Chemical Co., St. Louis, MO) to the preformed complex resulted in a change in the electrophoretic mobility from low (lane $C$ ) to high (lane $A P$ ) mobility (Fig. 3, lower left panel). These data suggest that the cytoplasmic activity present in peripheral blood CML myeloid cells that alters the mobility of DNA-nuclear protein complexes may be an acid phosphatase.

The levels of activity that alter nuclear protein-DNA complex mobility are different in the early and late stages of myeloid maturation. The nuclear proteins of Daudi cells were added in a 1:1 ratio (by weight) to the cytoplasmic proteins isolated from marrow cells belonging to early (blasts and promyelocytes) or late (bands and neutrophils) stages of myeloid maturation and incubated at $22^{\circ} \mathrm{C}$ for $1 \mathrm{~h}$ in the presence of inhibitors of the protease aprotinin, benzamidine, and PMSF.
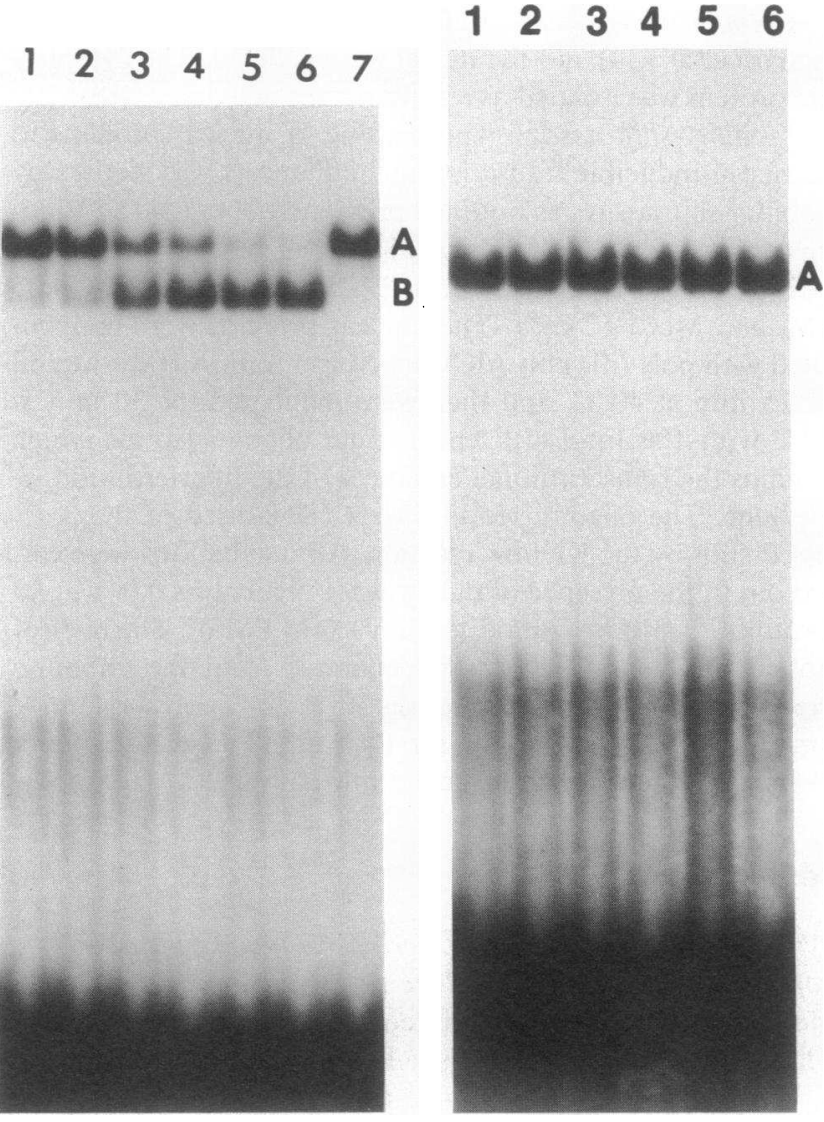

Figure 2. Effect of temperature on the CML cytoplasmic protein-induced alteration of the electrophoretic mobility of nuclear protein transcriptional enhancer complexes. Cytoplasmic proteins from the peripheral blood myeloid cells of a CML patient were added in a 1:1 ratio (by weight) to nuclear proteins purified from the Daudi lymphoid cell line and electrophoresed under nondenaturing conditions. Lymphoid nuclear proteins have been shown to form a low-mobility complex (band $A$ ) with interferon-inducible transcriptional enhancers (see Fig. 1). This mixture of lymphoid nuclear and cytoplasmic proteins of $\mathrm{CML}$ myeloid cells was incubated at $22^{\circ} \mathrm{C}$ (left) or at $4^{\circ} \mathrm{C}($ right) for $10,20,30,40,50$, and $60 \mathrm{~min}$, respectively (lanes $1-6$, both panels) in the presence of the protease inhibitors, aprotinin, benzamidine, and PMSF. Then an end-labeled oligonucleotide which contains the interferon-inducible enhancer from the 2,5-OAS or other interferon-inducible genes was added and the complexes formed were separated electrophoretically under nondenaturing conditions as described in the methods. Band $A$ (lane 7 in left panel) is the mobility of the DNA-protein complex formed by the Daudi cell nuclear protein with the 2,5-OAS enhancer alone. Band $B$ (left panel) is the complex generated with the 2,5-OAS transcriptional enhancer after exposure of the Daudi cell nuclear protein to the cytoplasmic protein of the CML myeloid cell. The unbound oligonucleotide is seen at the bottom of each lane. The nuclear proteins were preincubated with poly (dI) poly (dC) in each case.

Percoll gradients were used to collect the marrow myeloid cells belonging to early or late stages of myeloid maturation. The treated nuclear proteins were then incubated with the 2,5-OAS transcriptional enhancer. The changes induced in the electrophoretic mobility of nuclear protein-DNA complexes by the cytoplasmic proteins of immature myeloid (myeloblast and 

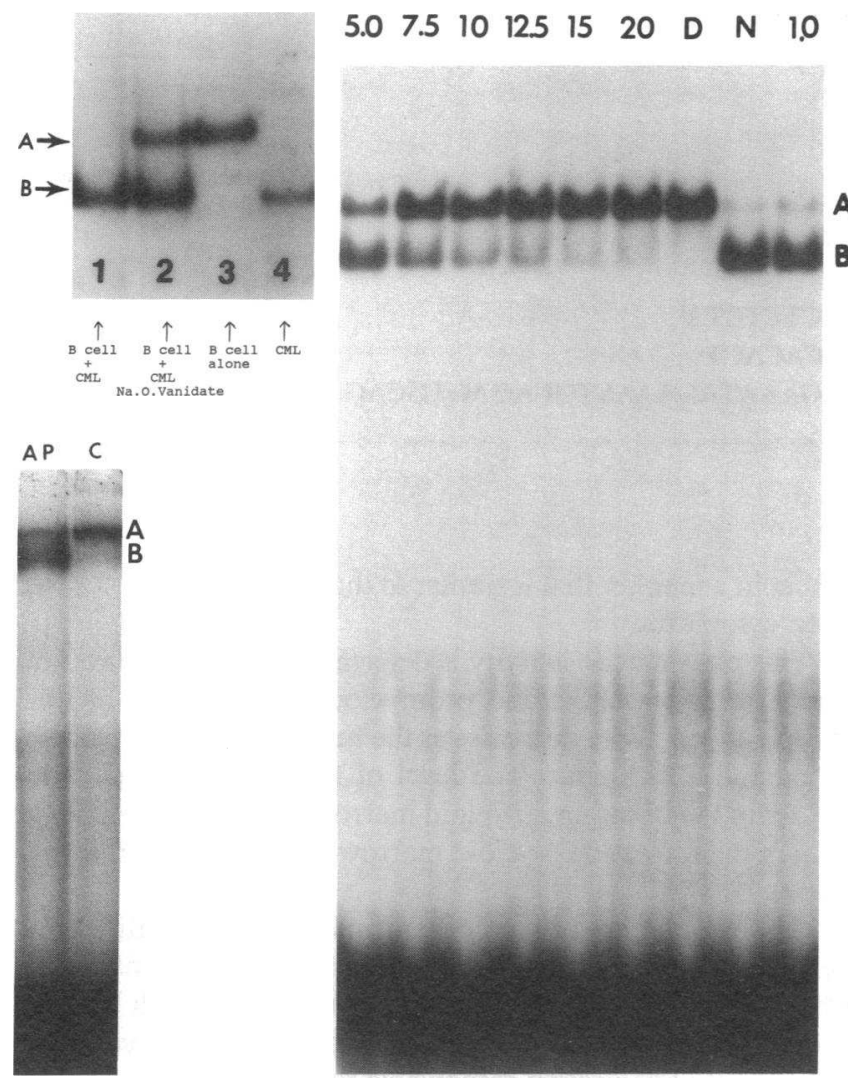

Figure 3. (Upper left) Effect of in vivo incubation with orthovanadate on cytoplasmic protein of CML peripheral blood cells on the electrophoretic mobility of nuclear protein-transcriptional enhancer complexes. We tested the effect of incubation of cells with orthovanadate on the activity in cytoplasmic proteins from CML cells. We measured the effect of cytoplasmic proteins from orthovanadate-treated cells on the electrophoretic mobility of complexes formed between lymphoid nuclear proteins and the interferon-inducible transcriptional enhancer of the 2,5-OAS gene using the mobility-shift assay. Lane 1: Electrophoretic mobility of the complex formed between an oligonucleotide which contains the 2,5-OAS transcriptional enhancer CTCCTCCCTTCTGAGGAAACGAAACCAACAGCAGT and the nuclear proteins of the Daudi cell. This complex was formed after these nuclear proteins were incubated in a 1:1 ratio by weight with cytoplasmic proteins from CML peripheral blood cells for $1 \mathrm{~h}$ at $22^{\circ} \mathrm{C}$. Lane 2: Electrophoretic mobility of complexes between the 2,5-OAS oligonucleotide and the Daudi cell nuclear protein after incubation of the Daudi nuclear proteins for $1 \mathrm{~h}$ in a $1: 1$ ratio with cytoplasmic proteins from CML peripheral blood cells previously incubated with $0.2 \mathrm{mM}$ of sodium orthovanadate. Lane 3: Electrophoretic mobility of the complex formed between Daudi nuclear proteins and the 2,5-OAS transcriptional enhancer. Lane 4: Electrophoretic mobility of the complex formed between the cytoplasmic proteins of CML peripheral blood myeloid cells and the 2,5-OAS transcriptional enhancer. Band $A$ is the low-mobility complex between nuclear proteins from Daudi and the interferon-inducible transcriptional enhancer. Band $B$ is the complex formed between the 2,5-OAS transcriptional enhancer and the lymphoid nuclear proteins which had been exposed to the cytoplasmic protein of CML peripheral blood cells. Identical results were obtained using Daudi nuclear proteins and the transcriptional enhancers of the 2,5-OAS, 6-16, 9-27, and $\beta_{2}$-microglobulin genes, as shown in Table I. Cell incubations were done in the presence of protease inhibitors aprotinin, benzamidine, and PMSF. (Right) Sodium orthovanadate inhibits the effect of cytoplasmic proteins on electrophoretic mobility of complexes promyelocyte) cells were then studied by the mobility-shift assay.

Scanning densitometry was used to determine the changes induced in these complexes by exposure to cytoplasmic proteins. The ratio of the high- (induced by exposure to cytoplasm) to low- (present before exposure to cytoplasm) mobility complex was determined by scanning densitometry of the autoradiograph of the mobility-shift assay. Little or no change in the electrophoretic mobility of the nuclear protein-transcriptional enhancer complexes was induced by the cytoplasm of mature myeloid (bands and polys) cells (lane 1 of Fig. 4), as judged by the ratio (0.13) of intensities of the high-mobility (band $B$ ) to low-mobility (band $A$ ) nuclear protein-DNA complexes. The addition of the cytoplasmic proteins of immature myeloid marrow cells (myeloblasts and promyeloblasts) of a chronic phase CML patient induced the formation of a new high-mobility complex (band $B$, lane 4 of Fig. 4) and decreased the intensity of the low-mobility complex (band $A$, lane 4 of Fig. 4). The ratio of the high- (band $B$ ) to low-mobility (band $A$ ) complexes with nuclear proteins exposed to cytoplasmic proteins from immature myeloid cells was 2.8 (see lane 4 of Fig. 4). These data suggest that the activity that alters electrophoretic mobility of nuclear protein-DNA complexes is high in immature myeloid cells and almost undetectable in mature myeloid cells.

formed between nuclear proteins and transcriptional enhancers. Sodium orthovanadate was added in vitro in varying concentrations to the cytoplasmic proteins after their isolation from CML peripheral blood cells. The nuclear proteins isolated from Daudi cells were then incubated in a 1:1 ratio (by weight) with the sodium orthovanadatetreated cytoplasmic proteins for $1 \mathrm{~h}$ at $22^{\circ} \mathrm{C}$. Poly (dI) poly (dC) at $0.1 \mathrm{mg} / \mathrm{ml}$ was added to the nuclear proteins for $15 \mathrm{~min}$ at $4^{\circ} \mathrm{C}$ and then the nuclear proteins were incubated with a ${ }^{32} \mathrm{P}$-labeled oligonucleotide which contained the 2,5-OAS interferon transcriptional enhancer for $1 \mathrm{~h}$ at $4^{\circ} \mathrm{C}$. The ${ }^{32} \mathrm{P}$-labeled oligonucleotide bound to the nuclear protein was separated from that unbound by electrophoresis in a mobility-shift gel. The concentration of the sodium orthovanadate in millimoles is listed above each lane. Lane $D$ has Daudi nuclear protein bound to the 2,5-OAS transcriptional enhancer without incubation to cytoplasmic proteins from myeloid cells. All other lanes contain Daudi nuclear proteins which have been exposed to myeloid cytoplasmic proteins. In lane $N$, no sodium orthovanadate has been added. Band $A$ denotes the position of the complex that forms in the absence of myeloid cytoplasmic protein. Band $B$ denotes the position of the complex that forms when Daudi nuclear proteins are exposed to myeloid cytoplasmic proteins. The unbound oligonucleotide is seen at the bottom of each lane. (Lower left) In vitro effect of acid phosphatase on the electrophoretic mobility of complexes formed between interferon-inducible transcriptional enhancers and the nuclear protein of Daudi cells. $9 \mathrm{U}$ of potato white acid phosphatase was incubated with the complex formed between the 2,5-OAS transcriptional enhancer and the nuclear proteins of the Daudi cell for $20 \mathrm{~min}$ at $22^{\circ} \mathrm{C}$. Lane $C$ (control): Electrophoretic mobility of the complexes before exposure to acid phosphatase in vitro; Lane $A P$ (acid phosphatase): Electrophoretic mobility of the complex after exposure to acid phosphatase in vitro. The free oligonucleotide is seen at the bottom of each lane. Nuclear proteins were incubated with $0.1 \mathrm{mg} / \mathrm{ml}$ of poly $(\mathrm{dI})$ poly $(\mathrm{dC})$ before incubation with the interferon-inducible transcriptional enhancers. 


\begin{tabular}{|c|c|c|c|}
\hline Gene & Sequence & $\begin{array}{l}\text { Position } 5^{\prime} \text { to } \\
\text { translation } \\
\text { start codon } \\
\text { (ATG) of gene }\end{array}$ & Reference \\
\hline 2,5-OAS & AGCTCCTCCСTTCTGAGGAAACGAAACCAACAGCAGTCCAA & -75 & 7 \\
\hline $\begin{array}{l}\beta_{2} \text {-micro- } \\
\text { globulin }\end{array}$ & AGACTCTAAGAAAAGGAAACTGAAAACGGAAAGTCССТСТСТСТА & -138 & 6 \\
\hline $9-27$ & ATTTACAAACAGCAGGAAATAGAAACTTAAGAGAAATACACACT & -143 & 8 \\
\hline $6-16$ & GAGCTGGGAGAGAGGGAAAATGAAACTGCAGAGTGCAGAAATAGAAACTGCAGAGTGCAG & -88 & 9 \\
\hline
\end{tabular}

Cytoplasmic activity that alters electrophoretic mobility of nuclear protein-DNA complexes is higher in immature CML myeloid cells than in immature myeloid cells of normal marrow. We then compared the level of the enzymatic activity that alters electrophoretic mobility of nuclear protein-DNA complexes in the cytoplasm of immature myeloid cells from the marrow of normal and CML individuals. To do this, the cytoplasmic protein from the immature myeloid cells of CML (lanes 2-7 of Fig. 5) or normal (lanes 9-14 of Fig. 5) individuals was added to the nuclear protein of Daudi cells. The ratio of the cytoplasmic protein/nuclear protein was varied from 1:10 (lanes 2,9) to $2: 1$ (lanes 7,14 ). We incubated these mixtures for $1 \mathrm{~h}$ at $22^{\circ} \mathrm{C}$ and then added the 2,5-OAS transcriptional enhancer to each mixture and ran a mobility gel as described in the methods. The marrow cells of the CML patient used for these studies were $100 \%$ positive for the Philadelphia chromosome. As shown in Table II and Fig. 5, the ratio of cytoplasmic protein/nuclear protein required to significantly change the electrophoretic mobility of the nuclear proteinDNA complexes was greater with the cytoplasmic protein from normal cells than was required with the cytoplasmic protein of CML myeloid cells. As judged by this assay, the effect of the cytoplasm of the CML cells was over four times that of the normal cells. This indicates that the concentration of the cytoplasmic enzymatic activity that altered the electrophoretic mobility nuclear protein-DNA complexes was greater in the CML blasts and promyelocytes than in the blasts and promyelocytes of normal individuals.

\section{Discussion}

Our studies have shown that the cytoplasm of peripheral blood myeloid cells of CML patients contains proteins that alter the electrophoretic mobility of complexes formed between nuclear proteins and interferon-inducible transcriptional enhancers. When the phosphatase inhibitor sodium orthovanadate was added to CML cells, the effect of these CML cytoplasmic proteins on the electrophoretic mobility of nuclear protein-DNA transcriptional enhancer complexes was diminished.

These experiments suggest that the cytoplasmic activity from CML myeloid cells, which alters the electrophoretic mobility of complexes between nuclear proteins and interferoninducible transcriptional enhancers, is a phosphatase. Direct addition of an acid phosphatase to nuclear proteins also altered the electrophoretic mobility of complexes between these nuclear proteins and interferon-inducible transcriptional en- hancer in a manner that is similar to that seen after exposure to CML cytoplasm.

This phosphatase activity is detectable in the cytoplasm of normal marrow blasts and promyelocytes. The level of this phosphatase activity decreases as the myeloid cells mature into bands and neutrophils. The level of this activity is fourfold greater in the immature myeloid marrow cells of CML patients than in the immature myeloid marrow cells of normal individuals.

There are at least two mechanisms for the generation of a new mobility-shift complex (band $B$ ) from the original complex (band $A$ in Fig. 1-5) after incubation of Daudi nuclear proteins with the cytoplasmic proteins of myeloid cells: $(a)$ There is a single protein responsible for the formation of both bands $A$ and $B$ which, in its phosphorylated form, travels as band $A$, and in its unphosphorylated form, travels as band $B$ after binding with the transcriptional enhancer; $(b)$ there are two distinct proteins which form bands $A$ and $B$ with the transcriptional enhancer. The protein that forms band $A$ binds to the interferon-inducible transcriptional enhancer in a phosphorylated form. The second protein, which forms band $B$ after phosphatase treatment, is in a phosphorylated form before incubation with phosphatase, and unable to bind to or compete for binding with the protein that forms band $A$. After exposure to the phosphatase, the protein that forms band $A$ is converted to its unphosphorylated form and is competed for binding to the enhancer by the protein that forms band $B$, which in its unphosphorylated form, binds to the interferoninducible transcriptional enhancer. Experiments designed to resolve these two hypothesis are currently underway in our laboratory.

Phosphotyrosine-specific phosphatases have been reported to be present in the HL60 human leukemia cell line and to increase 11-fold when it is induced to differentiate (17). Normal mature myeloid cells have greater quantities of phosphotyrosine-specific phosphatases than do leukemia cells (18). These phosphatases appear to oppose the action of genes associated with tyrosine-specific protein kinase $(19,20)$, which inhibit maturation of hematopoietic cells (21). Previously reported tyrosine-specific protein phosphatases are present in terminally differentiated myeloid cells (neutrophils or bands) and are absent in proliferative immature myeloid precursors (blasts and promyelocytes) (22). This is consistent with their proposed role as mediators of differentiation and inhibitors of proliferative signals. These previously reported phosphotyrosine-specific phosphatases are generally reported not to be inhibitable by low concentrations $(20 \mu \mathrm{M})$ of orthovanadate but 


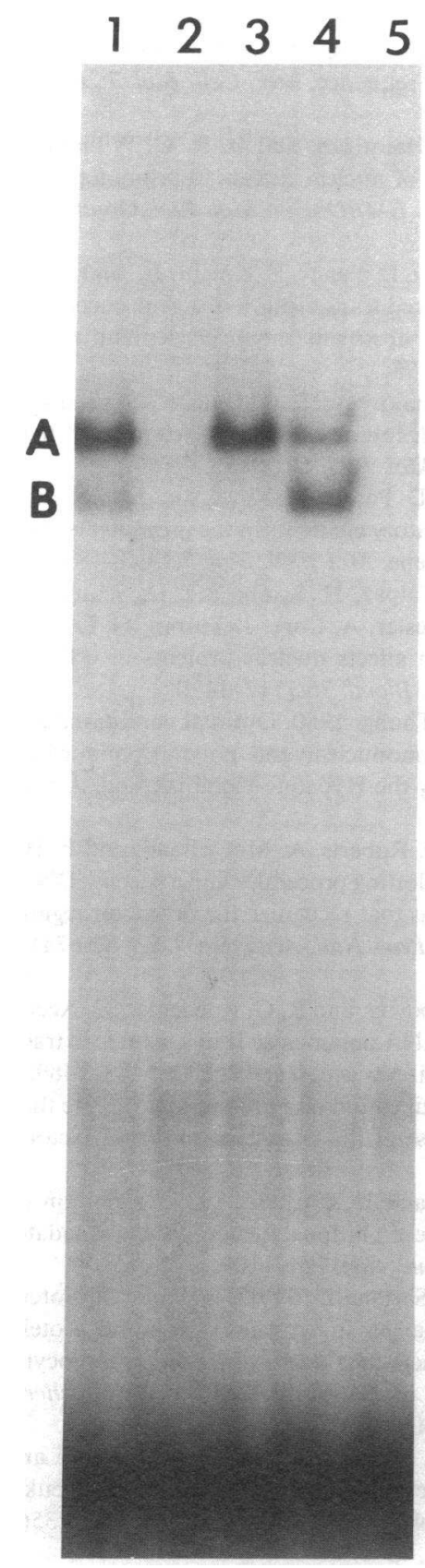

Figure 4. Immature myeloid cells contain more of the cytoplasmic activity that alters electrophoretic mobility of transcriptional enhancer nuclear protein complexes than do mature myeloid cells. $\mathrm{Nu}$ clear protein from the Daudi cell line was exposed in a 1:1 ratio for $40 \mathrm{~min}$ at $22^{\circ} \mathrm{C}$ to the cytoplasmic proteins of mature or immature myeloid cells isolated from the marrow of CML patients by Percoll gradients. The density at which the mature cells were isolated was $1.086 \mathrm{mg} / \mathrm{ml}$, whereas the density at which the immature myeloid cells were isolated was $1.062 \mathrm{mg} / \mathrm{ml}$. (The nuclear proteins were then incubated with the transcriptional enhancer of the 2,5-OAS gene in the presence of the protease inhibitors aprotinin, benzamidine, and PMSF.) Lane 1: Effect of cytoplasmic protein of mature myeloid cells of CML marrow (bands and neutrophils) on the electrophoretic mobility of Daudi nuclear protein-transcriptional enhancer complexes. Lane 2: Mobilityshift of cytoplasmic proteins of mature myeloid cells of CML marrow with 2,5-OAS transcriptional enhancer (little or no complex seen). Lane 3: Mobility-shift of nuclear proteins of Daudi cell line with 2,5-OAS transcriptional enhancer in the absence of cytoplasmic proteins. Lane 4: Effect of cytoplasmic protein of immature myeloid cells of CML marrow (blasts and promyelocytes) on the electrophoretic mobility of Daudi nuclear protein-transcriptional en-

hancer complexes. Lane 5: Mobility-shift of cytoplasmic proteins of immature myeloid cells (blasts and promyelocytes) of CML marrow with 2,5-OAS transcriptional enhancer (no complexes seen). Band $A$ designates the low-mobility complex which is formed by the nuclear proteins of the Daudi cell line and the 2,5-OAS transcriptional enhancer without exposure to cytoplasmic proteins. Band $B$ is the highmobility complex which is formed by the 2,5-OAS transcriptional enhancer and the Daudi nuclear proteins after exposure to cytoplasmic proteins of immature myeloid cells. The unbound ${ }^{32} \mathrm{P}$-labeled oligonucleotide is seen at the bottom of each lane. The nuclear proteins were incubated with $0.1 \mathrm{mg} / \mathrm{ml}$ of poly (dI) poly (dC) before addition to the oligonucleotides.

are inhibitable by concentrations of $\mathrm{Zn}^{2+}$ in the physiological range $(10-20 \mu \mathrm{M})(23,24)$.

The protein phosphatase that we have identified in CML cells is distinct from the phosphotyrosine phosphatases described previously (22). The phosphatases that we have identi-

\section{$\begin{array}{llllllllllllll}1 & 2 & 3 & 4 & 5 & 6 & 7 & 8 & 9 & 10 & 11 & 12 & 13 & 14\end{array}$}

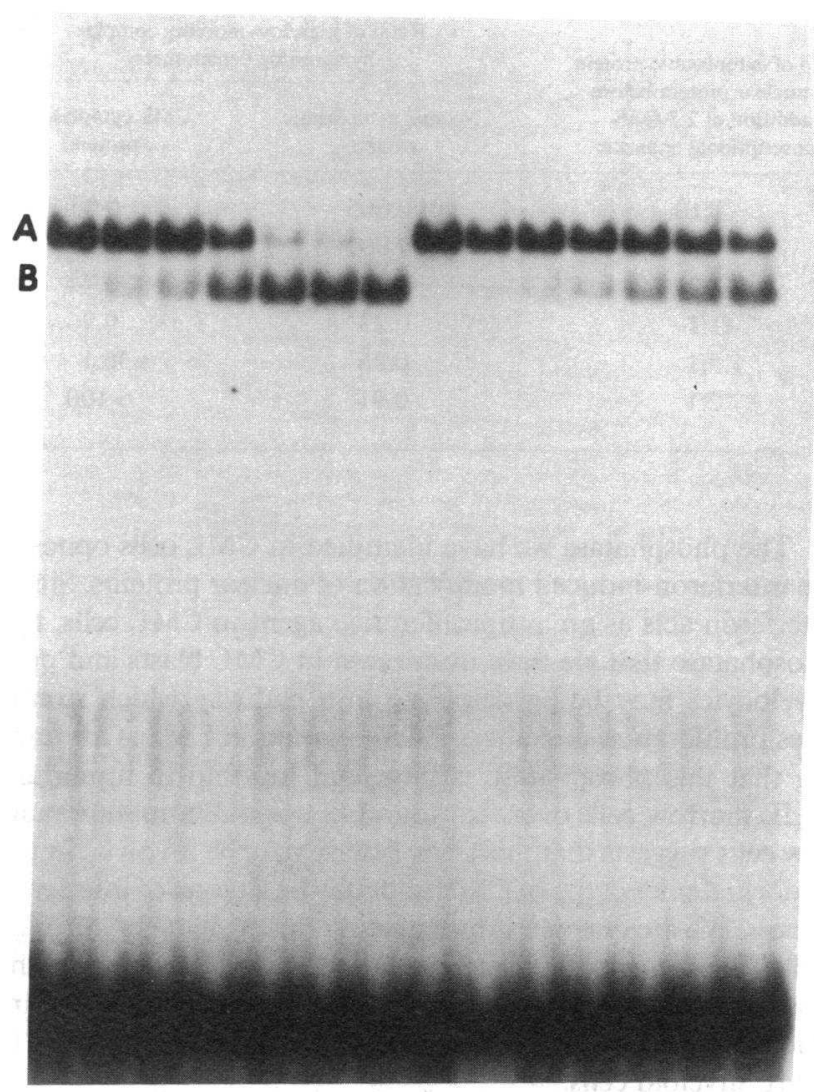

Figure 5. Immature myeloid cells of CML marrow contain more of the activity that alters electrophoretic mobility of complexes than do immature myeloid cells of normal marrow. Nuclear proteins of Daudi cells were incubated with the cytoplasmic protein of immature myeloid cells (blasts and promyelocytes) of the marrow of a CML (lanes 2-7) or normal (9-14) individual for $1 \mathrm{~h}$ at $22^{\circ} \mathrm{C}$. These proteins were then added to the 2,5-OAS transcriptional enhancer and mobility-shift gels run at $5 \mathrm{~V} / \mathrm{cm}$ for $16 \mathrm{~h}$. Lanes 2-7 contained $0.5,1.0,2.5,5,7.5$, and $10 \mu \mathrm{g}$ of cytoplasmic protein, respectively, of the immature myeloid marrow cells of a CML individual. Lanes 9-14 contained $0.5,1.0,2.5,5,7.5$, and $10 \mu \mathrm{g}$, respectively, of cytoplasmic protein of immature (blasts and promyelocytes) myeloid marrow cells of a normal individual. $5 \mu \mathrm{g}$ of Daudi nuclear protein was added to each lane. The complex formed by Daudi nuclear protein with interferon-inducible transcriptional enhancers in the absence of cytoplasmic protein is labeled (lanes 1 and 8 ). When $5 \mu \mathrm{g}$ of cytoplasmic protein of the CML or normal blasts were incubated with the 2,5-OAS enhancer, no complex was detected (see lane 5 of Fig. 4). All experiments were conducted in the presence of the protease inhibitors aprotinin, benzamidine, and PMSF. The unbound ${ }^{32} \mathrm{P}$-labeled oligonucleotide is seen at the bottom of each lane. The nuclear proteins were incubated with $0.1 \mathrm{mg} / \mathrm{ml}$ of poly (dI) poly (dC) before addition to the oligonucleotide.

fied are present in immature but not mature myeloid cells. The opposite is true of the phosphotyrosine-specific phosphatases previously reported (22). Initial purification and characterization of the substrate specificity of the phosphatase that we have found in immature myeloid cells and in CML suggest that it may be a novel phosphatase with properties different from those previously reported (Johnson and Deisseroth, unpublished observations). 
Table II. Comparative Ratios

\begin{tabular}{ccc}
\hline & \multicolumn{2}{c}{$\begin{array}{c}\text { Ratio of high/low-mobility complex } \\
\text { by scanning densitometry }\end{array}$} \\
\cline { 2 - 3 } $\begin{array}{c}\text { Ratio of cytoplasmic protein } \\
\text { to nuclear protein before } \\
\text { addition of 2,5-OAS } \\
\text { transcriptional enhancer }\end{array}$ & $\begin{array}{c}\text { Normal cytoplasmic } \\
\text { protein }\end{array}$ & $\begin{array}{c}\text { CML cytoplasmic } \\
\text { protein }\end{array}$ \\
\hline $1: 10$ & 0.005 & 0.03 \\
$1: 5$ & 0.002 & 0.14 \\
$1: 2$ & 0.06 & 0.74 \\
$1: 1$ & 0.23 & 9.96 \\
$1.5: 1$ & 0.36 & 36.1 \\
$2: 1$ & 0.91 & $>100$
\end{tabular}

The phosphatase we have identified in CML cells opposes the interferon-induced modification of nuclear proteins. Since interferon acts as an antiproliferative agent in CML cells, the phosphatase that we have discovered in CML blasts and promyelocytes may be participating in a pathway which stimulates proliferation and alters differentiation in CML. Our finding that this phosphatase is increased fourfold in immature CML marrow cells over that found in normal immature marrow cells suggests that this phosphatase may be involved in the abnormal phenotype of CML and may be a target of interferon action. We are currently investigating the mechanism through which the phosphatase becomes elevated in CML cells and the possible role of this phosphatase in limiting the interferon-induced activation of expression of interferon-inducible genes in CML myeloid cells.

\section{Acknowledgments}

The authors are grateful for the technical assistance of April Durett and the typing of the manuscript by Rosemarie Lauzon.

This work was supported by grants to Dr. Albert Deisseroth from the American Cancer Society (IM-580), the National Cancer Institute (PO1 CA49639-O1A1), the Kleberg Foundation, the Sid Richardson Foundation, and the Gillson-Longenbaugh Foundation. Interferon- $\alpha$ was a gift from Michael Shepard of Genentech, Inc., S. San Francisco, CA.

\section{References}

1. Fialkow, P. J., and J. W. Singer. 1989. Chronic leukemias. In Cancer: Principles and Practice of Oncology, Volume 2, 3rd edition. V. DeVita, S. Hellman, and S. A. Rosenberg, editors. J. B. Lippincott Co., Philadelphia. 1836-1852.

2. Thomas, E. D., R. A. Clift, A. Fefer, F. Appelbaum, P. Beatty, W. I. Bensinger, C. D. Buckner, M. A. Cheever, H. J. Deeg, K. Doney, et al. 1986. Marrow transplantation for the treatment of chronic myelogenous leukemia. Ann. Intern Med. 104:155-163.

3. Talpaz, M., H. Kantarjian, R. Kurzrock, J. Trujillo, and J. Gutterman. 1989. Sustained complete cytogenetic responses among Philadelphia positive CML patients treated with alpha-interferon. Blood. 74:79a. (Abstr.)

4. Storb, R. 1989. Bone marrow transplantation. In Cancer: Principles and Practice of Oncology, 3rd edition, Section 6. V. DeVita, S. Hellman, and S. A. Rosenberg, editors. J. B. Lippincott Co., Philadelphia. 2474-2489.

5. Talpaz, M., H. Kantarjian, K. McCredie, J. Trujillo, M. J. Keating, and J. U. Gutterman. 1986. Hematologic remission and cytogenetic improvement induced by recombinant human interferon alpha in chronic myelogenous leukemia. N. Engl. J. Med. 314:1065-1069.
6. Sugita, K., J.-I. Miyazaki, E. Appella, and K. Ozato. 1987. Interferons increase transcription of a major histocompatibility class I gene via a 5 ' interferon consensus sequence. $\mathrm{Mol}$. Cell. Biol. 7:26252630.

7. Rutherford, M. N., G. E. Hannigan, and B. R. G. Williams. 1988. Interferon-induced binding of nuclear factors to promoter elements of the 2,5A synthetase gene. EMBO (Eur. Mol. Biol. Organ.) J. 7:75.1-759.

8. Reich, N., B. Evans, D. Levy, D. Fahey, E. Knight, Jr., and J. E. Darnell, Jr. 1987. Interferon-induced transcription of a gene encoding a 15-kDa protein depends on an upstream enhancer element. Proc. Natl. Acad. Sci. USA. 84:6394-6398.

9. Porter, A. C. G., Y. Chernajovsky, T. C. Dale, C. S. Gilbert, G. R. Stark, and I. M. Kerr. 1988. Interferon response element of the human gene 6-16. EMBO (Eur. Mol. Biol. Organ.) J. 7:85-92.

10. Benech, P., M. Vigneron, D. Peretz, M. Revel, and J. Chebath. 1987. Interferon-responsive regulatory elements in the promoter of the human 2',5' oligo(A) synthetase gene. Mol. Cell. Biol. 7:4498-4504.

11. Howard, O. M. Z., M. Talpaz, H. Kantarjian, D. Seong, A. Wedrychowski, N. Paslidis, J. Hester, A. Cork, J. Turpin, G. LopezBerestein, et al. 1990. Interferon affects nuclear proteins in cells of clinically sensitive CML patients. Blood. 76:1117-1130.

12. Ferrante, A., and Y. H. Thong. 1980. Optimal conditions for simultaneous purification of mononuclear and polymorphonuclear leucocytes from human blood by the Hypaque-Ficoll method. J. Immunol. Methods. 36:109-117.

13. Miskimens, W. K., M. P. Roberts, A. McClelland, and F. H. Ruddle. 1985. Use of a protein-blotting procedure and a specific DNA probe to identify nuclear proteins that recognize the promoter region of the transferrin receptor gene. Proc. Natl. Acad. Sci. USA. 82:67416744.

14. Dignam, J. D., R. M. Lebovitz, and R. G. Roeder. 1983. Accurate transcription initiation by RNA polymerase II in a soluble extract from isolated mammalian nuclei. Nucleic Acids Res. 11:1475-1489.

15. Treisman, R. 1986. Identification of a protein binding site that mediates transcriptional response of the c-fos gene to serum factors. Cell. 46:567-574.

16. Swarup, G., S. Cohen, and D. Garbero. 1982. Inhibition of membrane phosphotyrosyl-protein phosphatase activity by vanadate. Biochem. Biophys. Res. Commun. 107:1104-1109.

17. Frank, D. A., and A. C. Sartorelli. 1986. Regulation of protein phosphotyrosine content by changes in tyrosine kinase and protein phosphotyrosine phosphatase activities during induced granulocytic and monocytic differentiation of HL-60 leukemia cells. Biochem. Biophys. Res. Commun. 140:440-447.

18. Kraft, A. S., and R. L. Berkow. 1987. Tyrosine kinase and phosphotyrosine phosphatase activity in human promyelocytic leukemia cells and human polymorphonuclear leukocytes. Blood. 70:356362.

19. Tonks, N. K., C. D. Diltz, and E. H. Fischer. 1988. Purification of the major protein-tyrosine-phosphatases of human placenta. J. Biol. Chem. 263:6722-6730.

20. Shriner, C. L., and D. L. Brautigan. 1984. Cytosolic protein phosphotyrosine phosphatases from rabbit kidney. J. Biol. Chem. 259:11383-11390.

21. Graf, T., N. Ade, and H. Beug. 1978. Temperature-sensitive mutant of avian erythroblastosis virus suggests a block of differentiation as mechanism of leukaemogenesis. Nature (Lond.). 275:496-501.

22. Shibata, K., J. Nishimura, H. Takahira, and H. Nawata. 1989. Phosphotyrosine phosphatase activity prevents the detection of P210 ${ }^{\mathrm{bcr} / \mathrm{abl}}$ protein in mature cells in chronic myelogenous leukemia even by an immunoblotting technique. Leukemia. 3:615-619.

23. Brautigan, D. L., P. Bornstein, and B. Gallis. 1981. Phosphotyrosyl-protein phosphatase. J. Biol. Chem. 256:6519-6522.

24. Gallis, B., P. Bornstein, and D. L. Brautigan. 1981. Tyrosylprotein kinase and phosphatase activities in membrane vesicles from normal and Rous sarcoma virus-transformed rat cells. Proc. Natl. Acad. Sci. USA. 78:6689-6693. 